\title{
Verzeichnis der durchgehend zitierten Kommentare, Hand- und Lehrbücher
}

Bamberger/Roth/Hau/Poseck, Beck'scher Online-Kommentar BGB, 57. Edition, 2021

Beck-Online Großkommentar zum Zivilrecht, $2020 \mathrm{f}$.

Brox/Walker, Allgemeines Schuldrecht, 45. Aufl., 2021

Dauner-Lieb, Das neue Schuldrecht: ein Lehrbuch, 2002

Dauner-Lieb/Konzen/Schmidt, Das neue Schuldrecht in der Praxis: Akzente, Brennpunkte, Ausblick, 2003

Dauner-Lieb/Langen, Nomos Kommentar BGB, 4. Auflage, 2021

Ehmann/Sutschet, Modernisiertes Schuldrecht, Lehrbuch der Grundsätze des neuen Rechts und seiner Besonderheiten, 2002

Emmerich, Recht der Leistungsstörungen, 6. Auflage, 2005; 5. Auflage, 2003

Erman, Bürgerliches Gesetzbuch, Band I, 15. Auflage, 2017; 16. Auflage, 2020

Esser/Schmidt, Schuldrecht, Allgemeiner Teil, Band I, Teilband 2, 8. Auflage, 2000

Esser/Weyers, Schuldrecht, Besonderer Teil, Band II, Teilband 1 und 2, 8. Auflage, 1998 und 2000

Fikentscher, Schuldrecht, 9. Auflage, 1997

Fikentscher/Heinemann, Schuldrecht, 11. Auflage, 2017

Gernhuber, Das Schuldverhältnis, 1989

Haas/Medicus/Rolland/Schäfer/Wendtland, Das neue Schuldrecht, 2002

Hirsch, Schuldrecht Allgemeiner Teil, 11. Auflage 2018

Heck, Grundriß des Schuldrechts, 1929

Henssler/v. Westphalen, Praxis der Schuldrechtsreform, 2. Auflage, 2003

P. Huber/Faust, Schuldrechtsmodernisierung, 2002

U. Huber, Leistungsstörungen Band I und Band II, 1999

Jauernig, BGB, 18. Auflage, 2021

Joussen, Schuldrecht I - Allgemeiner Teil, 5. Auflage, 2018

Koller/Roth/Zimmermann, Schuldrechtsmodernisierungsgesetz 2002

Lange/Schiemann, Schadensersatz, 3. Auflage, 2003

Larenz, Lehrbuch des Schuldrechts, Allgemeiner Teil, Band I, 14. Auflage, 1987

Larenz, Lehrbuch des Schuldrechts, Besonderer Teil, Band II, Halbband 1, 13. Auflage, 1986

Larenz/Canaris, Lehrbuch des Schuldrechts, Besonderer Teil, Band II, Halbband 2, 13. Auflage, 1994

Looschelders, Schuldrecht Allgemeiner Teil, 18. Auflage, 2020

Lorenz/Riehm, Lehrbuch des neuen Schuldrechts, 2002

Medicus, Schuldrecht I, Allgemeiner Teil, 12. Auflage, 2000

Medicus/Lorenz, Schuldrecht I, Allgemeiner Teil, 21. Auflage, 2015

Medicus/Petersen, Bürgerliches Recht, 27. Auflage, 2019

Münchener Handbuch zum Arbeitsrecht, 2. Auflage, 2000; 3. Auflage, 2012

Münchener Kommentar zum Bürgerlichen Gesetzbuch, 4. Auflage, 2000 ff.; 5. Auflage, 2007 f.; 8. Auflage, $2018 \mathrm{f}$.

8. Auflage, 2018 f.Oetker/Maultzsch, Vertragliche Schuldverhältnisse, 5. Auflage, 2018

Palandt, Bürgerliches Gesetzbuch, 61. Auflage, 2002; 80. Auflage, 2021

Planck, Plancks Kommentar zum Bürgerlichen Gesetzbuch nebst Einführungsgesetz, Band 2/1, Recht der Schuldverhältnisse (Allgemeiner Teil), §§ 241-432, 4. Auflage, 1914 
$\mathbf{X L}$ Verzeichnis der durchgehend zitierten Kommentare, Hand- und Lehrbücher

Prütting/Wegen/Weinreich, BGB Kommentar, 15. Auflage, 2020

Schmidt-Räntsch, Das neue Schuldrecht, 2001

Schlechtriem, Schuldrecht, Allgemeiner Teil, 4. Auflage, 2000

ders./Schmidt-Kessel, Schuldrecht, Allgemeiner Teil, 6. Auflage, 2005

Schmoeckel/Rückert/Zimmermann, Historisch-kritischer Kommentar zum BGB, $2003 \mathrm{ff}$.

Schulze/Dörner/Ebert u.a., BGB-Handkommentar, 10. Auflage, 2019

Soergel, Bürgerliches Gesetzbuch mit Einführungsgesetzen und Nebentexten, 12. Auflage, $1987 \mathrm{ff} . ; 13$. Auflage, $1999 \mathrm{ff}$.

Staudinger, Kommentar zum Bürgerlichen Gesetzbuch mit Einführungsgesetzen und Nebengesetzen, 13. Bearbeitung $1993 \mathrm{ff}$; Neubearbeitung $2018 \mathrm{ff}$.

Neuner, Allgemeiner Teil des Bürgerlichen Rechts, 12. Auflage, 2020 